Kai A. Konrad *

Florian Morath **

\title{
Social Mobility and Redistributive Taxation
}

* Max Planck Institute for Intellectual Property, Competition and Tax Law and WZB

** Max Planck Institute for Intellectual Property, Competition and Tax Law

SP II 2010 - 15

October 2010 
Kai A. Konrad, Florian Morath, Social Mobility and Redistributive Taxation, Discussion Paper SP II 2010 - 15, Wissenschaftszentrum Berlin, 2010.

Wissenschaftszentrum Berlin für Sozialforschung $\mathrm{gGmbH}$, Reichpietschufer 50, 10785 Berlin, Germany, Tel. (030) 25491 - 0 Internet: www.wzb.eu 


\section{Social Mobility and Redistributive Taxation}

by Kai A. Konrad and Florian Morath *

We investigate redistributive taxation in a political economy experiment and determine how different patterns of social mobility affect the choices of redistributional taxes. In the absence of social mobility, voters choose tax rates that are very well in line with the prediction derived in the standard framework by Meltzer and Richard (1981). However, past or future changes in the income hierarchy affect the choice of the tax rate in the current period. The same is true for social mobility within the period to which the tax rate choice applies and for the case where the choice of the tax rate takes place behind the veil of ignorance. Due to our design of the experiment, these strong effects of own social mobility cannot be attributed to social or other-regarding preferences.

Keywords: Median voter, redistribution, social mobility

JEL classification: D72, D78, H20

ZUSAMMENFASSUNG

\section{Soziale Mobilität und Einkommensumverteilung}

Dieser Artikel untersucht Besteuerung mit dem Ziel der Einkommensumverteilung in einem polit-ökonomischen Experiment. Wir ananlysieren, wie unterschiedliche Muster sozialer Mobilität die Wahl von Steuern bestimmt, die zur Umverteilung dienen. Ohne die Möglichkeit eines sozialen Auf- oder Abstiegs entscheiden sich die Wähler für Steuersätze, die der theoretischen Vorhersage des Standardmodells von Meltzer und Richard (1981) entsprechen. Mobilität in der Einkommenshierarchie - sowohl in der Vergangenheit als auch in der Zukunft - hat jedoch einen signifikanten Einfluss auf die Wahl des Steuersatzes in der gegenwärtigen Periode. Dies gilt auch, wenn die Möglichkeit sozialer Mobilität in derjenigen Periode besteht, in der der Steuersatz zur Anwendung kommt. Ebenso verändert sich die Wahl des Steuersatzes, wenn die Entscheidung hinter dem „Schleier der Unwissenheit“ vorgenommen wird. Aufgrund des Aufbaus des Experiments können diese starken Effekte eigener sozialer Mobilität nicht durch soziale Präferenzen begründet sein.

\footnotetext{
* Financial support of LMUexcellent is gratefully acknowledged. For providing laboratory resources we kindly thank MELESSA of the University of Munich.
} 


\section{Introduction}

What explains the distribution and redistribution of income? This has been a fundamental question ever since the early days of economics and political science. Addressing this question, Meltzer and Richard (1981) combined ideas about the distribution of abilities, income earning incentives and market forces with political institutions and political decision-making. In this paper, we investigate experimentally this concept of voting on redistribution, and we examine how different patterns of social mobility affect the choices of redistributional taxes.

The seminal theory developed by Meltzer and Richard (1981) rests on a concept of rational citizens who maximize their own, narrowly defined interests. In the economic sphere they choose their own work effort given their individual abilities and given the regime of redistributional taxation currently in place. In the political sphere they vote on the regime of redistributional taxation. Applying median voter theory and assuming that the median voter anticipates the distortion effects and redistribution effects of a higher tax rate, Meltzer and Richard predict an outcome in which the tax rate chosen just balances the marginal benefit and cost which an increase of the redistributive tax have for the median voter. The level of redistribution increases with the ratio of the mean income in society to the income of the median voter. ${ }^{1}$

Many further motivations and aspects of wage-earning activities and electoral choices about redistribution have been considered in the three decades since 1981. ${ }^{2}$ First, intertemporal considerations and the dynamics of own income generating ability may play a role. Individuals who are currently well-off may like to commit to a system of income redistribution if they fear that they may lose their high income position and become the beneficiaries

\footnotetext{
${ }^{1}$ In the presence of imperfect insurance markets, however, inequality can have a nonmonotonic effect on redistributive preferences (Bénabou 2000). Moreover, if welfare expenditures are targeted to the poor, inequality negatively affects the support for redistribution (Moene and Wallerstein 2001).

${ }^{2}$ See, e.g., Rehm (2009) for a related classification.
} 
of this redistribution in the future. Redistribution may then have the role of insurance for them (Varian 1980). Similarly, currently poor individuals may favor income redistribution less strongly if they feel that they (or their children) may rise in the income hierarchy in future periods (Piketty 1995). Second, preferences about status, positional concerns or other-regarding preferences may be important. There is potentially a large number of motives behind such preferences. They can be based on feelings of altruism, envy or other types of relative-standing comparisons. ${ }^{3}$ Preferences about relative standing or status may be subject to the prevailing institutional or historical framework, or norms that have evolved. The willingness to share with others may depend on the perceptions of social mobility that prevail in a society (Bénabou and Ok 2001). Third, citizens may have what could be called "social preferences" about how the distribution of incomes should look like. Determinants of such preferences may, for instance, be feelings of empathy, group identity, national identity or solidarity. ${ }^{4}$ Also, whether individuals perceive income distribution as a result of individual effort ("merit"), or as a result of pure chance, may affect their distributional preferences and their views about redistribution. ${ }^{5}$ Such motivations may add to, counteract, or cloud the basic underlying logic of the Meltzer-Richard concept.

In our analysis, we first ask whether the simple and intuitively compelling theory of Meltzer and Richard (1981) holds if income earning and voting

\footnotetext{
${ }^{3}$ Such considerations have a long history in social science. In economics, relativestanding comparisons have been recognized by Veblen (1899) and their consequences have been developed more formally, e.g. by Frank (1984, 1985), Glazer and Konrad (1996), Fershtman and Weiss (1996), and Fehr and Schmidt (1999), among others.

${ }^{4}$ The idea of moral sentiments is, evidently, very old in the history of ideas. It has been given formal consideration, for instance, by Hochman and Rogers (1969). Recent work by Shayo $(2006,2009)$ suggests that preferences about redistribution may be linked to concepts of social or national identity.

${ }^{5}$ Piketty (1995) analyzes the role of own mobility history for redistributional preferences. His research focuses on the role of beliefs about whether economic success is predetermined or whether individual effort is more important for economic achievements for individuals' preferences on redistribution. See Isaksson and Lindskog (2009) for an international comparison.
} 
on redistribution takes place in an experimental laboratory and under ideal conditions. In a framework in which the three additional sets of motivations are absent by construction, we find: individuals seemingly understand the structure of the Meltzer-Richard problem, and they behave accordingly. They follow their material interests when choosing their income-generating efforts. They also understand the consequences of their electoral choices and vote in line with their material interest. They seemingly can see through the fiscal veil of taxation and redistribution and correctly anticipate the consequences of higher taxes for other individuals' work effort, and what this implies for redistribution. This provides the benchmark and an important reference point for the second set of questions we ask.

The second set of questions addresses aspects of income mobility and how income mobility affects voting on redistributional taxes. We compare three different mobility regimes to our benchmark case where individuals have a constant ability/productivity throughout all rounds of the experiment. In the first mobility regime, the ability of individuals randomly fluctuates from one round to another, but is known with certainty within one round. Does this perceived social mobility affect the subjects' choices of the redistributive tax even if the electoral choice of the redistributive tax takes place each round and applies only to the current round? In the second mobility regime, when voting on redistribution, individuals have a signal, but not perfect information about their productivity at the point in time when income can be earned. Thus, contrary to the first mobility regime, there is actual income mobility within one round of the experiment. In the third mobility framework, the choice of taxes occurs under a complete veil of ignorance: individuals know the income distribution in society, but not their own income.

In the first mobility regime, perceived mobility has an effect on the choices of the tax rate, and median tax rates are significantly lower than in the benchmark case. The same is true for the second mobility regime; here, under actual social mobility, median tax rates are similar to those in the 
first mobility regime under perceived social mobility. In the third mobility regime, behind a veil of ignorance, we identify two different types of behavior: almost one half of the subjects take into account the tax distortion effects and choose tax rates in line with their material interest; the other half of the subjects state tax rates that are very close to the average of potentially optimal future tax rates. By and large, the different types of mobility have effects that are in line with narrowly selfish electoral and earnings choices.

Measurement of policy choices on redistributive taxation in countries, or by questionnaires about preferences for redistribution and the like, have limits that suggest laboratory experiments as an important complementary tool. The experimental setup has three important advantages for studying these questions.

First, it is difficult to identify the Meltzer-Richard logic in the empirical data, given that it could be clouded by all the other effects discussed above. In the laboratory, individuals can be placed in a framework in which most or all aspects that add, counteract or potentially conceal this logic can be controlled for or removed. We use a simple device for removing all status considerations and possible types of other-regarding preferences from the picture.

Second, for the Meltzer-Richard logic to materialize it would be important for voters to anticipate the equilibrium behavior of the vast majority of other individuals. The choice of tax rate that maximizes their material payoff is, for instance, lower (higher) if the tax is more (less) distortionary for actual behavior than what it should be from the perspective of a worker who chooses his labor supply according to narrowly defined selfish interests. This type of 'strategic uncertainty' can also be controlled for in the laboratory, by embedding the subjects in a computer-simulated environment. At the same time, this setup eliminates any repeated games effects.

Third, for the Meltzer-Richard logic to emerge it is important that the conditions of the median voter theorem apply. There are numerous rea- 
sons why the median voter outcome need not emerge in the 'field', ranging from standard types of violations of assumptions made for the median voter theorem (one-dimensional policy space, single-peaked preferences) to issues such as parties' ability to commit, accountability, and candidate competence issues, voter abstention, expressive voting (Glazer 1987, Huck and Konrad 2005, Feddersen et al. 2009) or other types of non-sincere voting.

Empirical evidence on the Meltzer-Richard (1981) theory is inconclusive. Neustadt and Zweifel (2009), for instance, find that Swiss citizens' demand for redistribution increases with income and higher self-positioning, which they interpret as being in contradiction with the Meltzer-Richard (1981) model. Krusell and Ríos-Rull (1999) argue that their calibration model of a dynamic Meltzer-Richard framework predicts transfers that are "quite close" to empirical data. Moene and Wallerstein (2003) show that deviations from the Meltzer-Richard prediction on the impact of inequality can be explained by distinguishing among different categories of welfare spending. Given the large number of aspects that add and potentially obliterate the benchmark effects, inconclusive evidence should not be surprising.

Existing experimental analyses of income redistribution focus mainly on other-regarding preferences. Krawczyk (2010), for instance, studies the revealed preferences for redistribution of randomly generated income if individuals know their mutual probabilities of winning a high income. He finds that differences in win probability do not lead to stronger preferences for redistribution, but that more redistribution was preferred by the subjects if the win probability was randomly assigned ("luck") than if it was the outcome of individual effort/ability ("merit"). Similarly, the experiment by Durante and Putterman (2009) focuses on the role of fairness considerations in a framework in which players choose redistributional taxes. Further important experimental work on voting on redistribution has been done by Tyran and Sausgruber (2006), who analyze a case where subjects endowed with different income levels vote on a fixed amount of redistribution. They find that 
Fehr-Schmidt-type inequity aversion may explain their experimental results on voting on redistribution.

Overall, the empirical and experimental literature suggests that interpersonal considerations matter for the politics of redistribution. For an experimental analysis of the motivations underlying the Meltzer-Richard results, we therefore consider an experimental design which eliminates any direct fairness considerations and income comparisons from the picture. An individual's tax choice affects the individual's own income earning effort and the efforts of computer-simulated subjects, but there are no other real subjects in the same experiment the individual could compare with or towards whom he could develop other-regarding feelings.

\section{The setup}

The framework that sets out the basis for the experiment follows closely the model by Meltzer and Richard (1981) - hereafter MR - with simplifications and minor adaptations. Suppose the economy consists of three individuals who act as voters and workers. Individuals only differ in their productivity, measured by the wage rate $w_{i}$, where $w_{i} \in\{0,3,6\}$.

The distribution of wages within the society is drawn - with equal probability - from the set $P$ of permutations of the tuple $(0,3,6)$. Thus, each individual has a probability of $1 / 3$ of having a wage of 0,3 , or 6 , and the aggregate wage distribution is the same for all possible random draws. To allow for social mobility, we assume that the distribution of wages for the upcoming working period may change after the tax rate has been chosen. This is the case, for instance, if a tax policy, once implemented, is more sticky than the distribution of wages. By construction, this allows for individual income mobility, but the distribution of incomes remains unchanged.

We consider the following two-stage game. At the beginning of stage 1, one element of $P$ is randomly drawn, and each individual learns his prospec- 
tive wage rate. Then, the individuals simultaneously state their preferred tax rate $\tau_{i} \in[0,1], i=1,2,3$, knowing that the median choice will be implemented. ${ }^{6}$

At the beginning of stage 2, with probability $p$, a new element of the set $P$ of possible wage distributions is chosen (possibly identical to the old one). With the remaining probability $1-p$, no reassignment of wages takes place. (In the basic MR game, $p=0$.) If the wage distribution has changed, individuals learn their new wage rate. In addition, individuals learn the implemented tax rate. Then, they simultaneously choose their work effort $x_{i} \geq 0, i=1,2,3$. The payoff of an individual only depends on the final wage rate valid in stage 2 and is equal to

$$
\pi_{i}=(1-\tau) w_{i} x_{i}-\frac{1}{2} x_{i}^{2}+\frac{1}{2} \sum_{j \neq i} \tau w_{j} x_{j} .
$$

It consists of three terms. First, an individual's gross income is equal to $w_{i} x_{i}$, and each individual pays a proportional tax $\tau$ on this income. Second, the individual bears an effort cost of generating income that rises with his own work effort and equals $\frac{1}{2} x_{i}^{2}$; this effort cost is not deductible from the tax base. Third, the tax revenue is solely used to finance lump-sum redistribution. More precisely, each individual $i$ receives a transfer that is equal to half of the tax revenue obtained from taxing the other individuals in his group. Note that the transfer which an individual receives does not depend on his own tax payment. ${ }^{7}$

Given the tax rate $\tau$ and the final wage rate $w_{i}$, maximizing $\pi_{i}$ in (1)

\footnotetext{
${ }^{6}$ Compared to the actual political process in a median voter framework, this is a shortcut which yields the same outcomes as predicted by the median voter theorem. As the number of voters is uneven, the tax rate is uniquely determined by the median choice.

${ }^{7}$ This redistribution mechanism makes sure that a player does not internalize any return on being taxed himself, which is the equivalent to a model with an atomless distribution of individuals.
} 
with respect to $x_{i}$ leads to an optimal choice of effort

$$
x^{*}\left(w_{i}\right)=(1-\tau) w_{i} .
$$

Note that this choice only depends on the tax rate and on the own final wage rate, and it is independent of $p$, since the wage rate is known with certainty when individuals choose their work effort.

Assuming subgame-perfect play, individuals maximize the expected payoff given the choice of work effort $x^{*}\left(w_{i}\right)$. The optimal choice of the tax rate depends on the probability $p$ that a new wage distribution will be assigned. Suppose first that $p<1$. Then, the individual that originally had been assigned the low wage $w=0$ always prefers a strictly positive tax rate as it is most likely that his final wage will be zero. The individual with the prospective wage $w=3$ prefers a strictly positive tax rate whenever his income is not higher than the mean income in the society. ${ }^{8}$ The individual, however, that originally had been assigned the high wage $w=6$ always prefers a tax rate of zero. The reason is as follows. With probability $1-p$, the individual keeps the high wage rate and prefers that there is no redistribution. With the remaining probability, there is an equal chance of obtaining either of the three possible wage rates; the optimal tax rate in this case is the one that maximizes expected surplus which, due to the tax distortion effects, is a tax rate of zero. With the same argument, if $p=1$ and the prospective wage becomes irrelevant, all individuals prefer a tax rate of zero.

When determining his preferred tax rate, the median voter trades off the increase in redistribution with the higher tax distortion. His preferred tax rate is decreasing in $p$ : the more likely it becomes that a new wage distribution will be assigned, the more important becomes the tax distortion effect when his expected payoff is maximized.

\footnotetext{
${ }^{8}$ If the three possible wages are $w_{l}<w_{m}<w_{h}$, then $\tau^{*}\left(w_{m}\right)>0$ if and only if $w_{m}^{2}<\left(w_{l}^{2}+w_{h}^{2}\right) / 2$. Note that $w_{m}^{2}<\left(w_{l}^{2}+w_{h}^{2}\right) / 2$ is fulfilled if $w_{m} \leq w_{h} / 2$.
} 
If $p=0$ (as in the basic MR game), the individuals' preferred tax rates ${ }^{9}$ are equal to

$$
\tau^{*}(w=0)=\frac{1}{2}, \tau^{*}(w=3)=\frac{1}{3}, \text { and } \tau^{*}(w=6)=0 .
$$

If $p=0.75$ (as we will choose in the experiment), this results in optimal tax rates

$$
\tau^{*}(w=0)=\frac{1}{4}, \tau^{*}(w=3)=\frac{1}{8}, \text { and } \tau^{*}(w=6)=0 .
$$

With social mobility, the preferred tax rate of both the individual with the low and the medium wage are lower than in the basic game. For $p=1$, the choice of the tax rate takes place behind the veil of ignorance; all three individuals prefer a tax rate of

$$
\tau^{*}=0
$$

Here, as discussed above, maximization of expected payoff corresponds to maximization of total expected surplus. ${ }^{10}$

\section{Experimental design}

The design of the experiment isolates, on the one hand, the effect of the individual income position on preferences for redistribution and identifies, on

\footnotetext{
${ }^{9}$ Note that in the equilibrium of the two-stage game, the tax rates chosen by the low and the high-wage individual are not uniquely determined, as they will not be implemented as long as they do not constitute the median choice. The notion "preferred tax rate" corresponds to the tax rate that, if implemented, maximizes an individual's monetary payoff, given that all individuals choose the payoff-maximizing effort in (2).

${ }^{10}$ Expected income (or its generalized version -expected utility- where the marginal utility is not constant across levels of income) is generally accepted as an objective by economists. However, as Rawls has argued, if the choice of the tax rate takes place behind the veil of ignorance, voters' preferences would represent fair opinions on redistribution, and he favoured a maximin social welfare function in this case. If voters indeed have maximin preferences, this would lead to a tax rate equal to the preferred tax rate of the voter with the low wage $(\tau=1 / 2)$.
} 
the other hand, the impact of perceived and actual own individual mobility on preferred tax rates. In the treatments with mobility, the change of own wage does not change the general wage distribution - by construction. The focus here is on the impact of (changes of) the voters' relative income position within the society. In a sense, whereas one could imagine that the income level of, e.g., the middle class relative to the high-income class could also change, we have in mind a situation where there is always a low-income, a middle-income and a high-income class with fixed (relative) wage rates, but exogenous shocks may change individuals' affiliation with either of these classes.

To have voting choices from individuals with low, middle and high wages, we grouped players into sets consisting of 3 voters: one with a low wage rate, one with a medium wage rate and one with a high wage rate. Only one of the three players in each set is a 'real' player; the co-players in this set are simulated by the computer. This was made common knowledge. Also, subjects knew that each simulated player maximizes his own monetary payoff. This approach eliminates the possible effects stemming from other-regarding preferences; in addition, it removes any strategic uncertainty about the coplayers' effort choices for a given tax rate and therefore allows for precise predictions about the behavior of one's co-players in a given set.

Each of the treatments consisted of 24 groups, each with one 'real player' and two 'simulated players'. One session consisted of 12 rounds. The BASE(LINE) treatment implements the framework of Meltzer and Richard (1981) setting $p=0$ : individuals know their wage with certainty when choosing the tax rate. Each individual was randomly assigned a wage rate at the beginning of the experiment, and the individuals knew that they would keep their wage rate throughout the entire experiment. Thus, the one-period voting game was played 12 times, each time with the same wage rate and the same wage distribution within a group.

The second treatment, the RAND(OM) treatment, is designed to identify 
the effect of past experience and future income mobility on preferences for redistribution, focusing only on "perceived mobility" and abstracting from "actual mobility". Here, again $p=0$, that is, individuals kept their wage rate within a round; they were, however, randomly assigned a new wage rate in each of the 12 rounds. The stage game therefore is identical to the stage game in the BASE treatment; rounds are completely independent, and there is no uncertainty about the individual income position within a given round. But in the RAND treatment, individuals experienced different wage rates in the past, and anticipated different income positions in the future. The theory predictions for this treatment are precisely the same as for the BASE treatment. However, this "perceived mobility" may already affect the voters' preferences for redistribution.

In the third treatment, the Moвi(LITY) treatment, we add the possibility of actual social mobility prior to a possible adjustment of the tax rate. As in the RAND treatment, individuals obtain a new randomly chosen wage rate in each new round. In addition, with probability $p=0.75$, wages are reassigned once the individuals have stated their preferred tax rate and before choosing their work effort.

The last treatment, called IGNo(RANCE), focuses entirely on the aspect of uncertain future income by assuming that individuals learn their wage rate only after having decided on the tax rate. (From a theory perspective, this corresponds to $p=1$ in the game above.) As there is perfect income mobility, this is equivalent to the choice of taxes taking place behind the veil of ignorance.

Table 1 summarizes the design of the experiment. The experiment was programmed and conducted with the experiment software $\mathrm{z}$-Tree (Fischbacher 2007) and run at the MELESSA lab of the University of Munich. The subjects (96 in total) were students from a large variety of fields of study. ${ }^{11}$ Earnings in the experiment were measured in a currency called "Taler". Before

\footnotetext{
${ }^{11}$ The participants were recruited using the software ORSEE (Greiner 2004).
} 


\begin{tabular}{llcc}
\hline \hline Treatment & Description & \# rounds & \# groups \\
\hline BASE(LINE) & $\begin{array}{l}\text { Subjects keep wage } \\
\text { throughout experiment }\end{array}$ & 12 & 24 \\
RAND(OM) & $\begin{array}{l}\text { Subjects randomly get } \\
\text { new wage each round }\end{array}$ & 12 & 24 \\
MoBI(LITY) & $\begin{array}{l}\text { Subjects get new wage } \\
\text { within round with prob. } \frac{3}{4}\end{array}$ & 12 & 24 \\
IGNo(RANCE) & $\begin{array}{l}\text { Subjects learn wage only } \\
\text { after choice of tax rate }\end{array}$ & 12 & 24 \\
\hline \hline
\end{tabular}

Table 1: Experimental design

the experiment started, the subjects had to answer questions regarding their understanding of the experiment; by answering the questions, they earned an endowment of 10 Taler. The exchange rate used in all treatments was 6 Taler $=1$ Euro.

Each of the four treatments consisted of 12 rounds. At the beginning of each round (except for the IGNO treatment), the subjects were informed of their wage in this round and remembered the wages of their co-players. In the MoBI treatment, it was indicated that, in 3 out of 4 cases, a new wage distribution would be assigned. Subjects were asked to state their preferred tax rate in percentage, as an integer between 0 and 100. The preferred tax rates of the two simulated voters within a group were chosen as to maximize the player's monetary payoff (this was commonly known). The finite number of rounds rules out possible repeated game effects for equilibrium play if players are motivated by material interests only. However, such effects may emerge nevertheless. We consider such effects as very unlikely in our environment, because subjects knew that they interact with independent computer-simulated players in each round, and these computer-simulated players maximize monetary payoffs in each single round. 
The computer selected the tax rate that was implemented in this round. With a probability of 0.8 , the computer selected the median choice, and with the remaining probability, the computer selected either the lowest or the highest of the three proposed tax rates within a group. This ensured that the individuals with low or high wage would have an (economic) interest to honestly state their preferred tax rate. The way the computer would select the tax rate implemented for the group was explained in the instructions. ${ }^{12}$

At the beginning of the second stage, the subjects learned the implemented tax rate, and, in treatments MoBi and IGno, their (possibly new) wage. They had to choose their work effort as a real number between 0 and 6 . At this point, the subjects were shown a cross table, computing for different possible choices of effort their gross income, the taxes they would have to pay, and their cost of effort. For the two simulated voters, the computer chose their payoff-maximizing work effort. At the end of each round, subjects were displayed their own preferred tax rate, the tax rate selected for their group, their own work effort, and their own monetary payoff in this round.

\section{Theoretical predictions}

Building on the theoretical framework, we first derive predictions on the subjects' voting behavior and effort choices in each treatment. Then, we compare the BASE treatment (where subjects keep their wage throughout the entire experiment) to the treatments with (perceived) social mobility.

The first two hypotheses focus on behavior within a given treatment. We predict that the observed effort choices are in line with the theory prediction given by (2).

\footnotetext{
${ }^{12}$ Note also that this deviation from the strict median voter framework does not affect the equilibrium choices of work effort in the theoretical framework in section 2 , as work effort is always chosen once the actual tax rate is known.
} 
Hypothesis 1 (Effort choice) In all treatments, the choice of work effort is equal to the theoretically predicted equilibrium effort.

Next, we predict that material interest drives the choice of the tax rate in the sense that preferred tax rates are strictly decreasing in the wage rate. Moreover, focusing on the choices of the median voter, we predict that median tax rates correspond to the theory prediction given in (3) for the BASE and the RAND treatment and in (4) and (5) for the MoBI and the IGNo treatment, respectively. The median voters' choices are most reliable as they are most likely the tax rates being selected within the group. Still we will discuss the choices of voters with low or high wage and compare them to the theoretically optimal choices.

Hypothesis 2 (Preferred tax rates) a) In the treatments BASE, RAND, and MовI, the preferred tax rate is strictly decreasing in the wage rate. b) In all treatments, the median voter's tax rate is equal to the theoretically predicted choice.

In the BASE and the RAND treatments, subjects know their wage when they choose the tax rate, and therefore risk preferences do not play any role. In the MoBI and the IGNo treatment, however, the subjects' preferred tax rates may depend on how subjects react to uncertainty. If we expect the subjects to exhibit (strong) risk aversion, median tax rates in the two latter treatments would be higher than the theory prediction in (4) and (5), respectively. For this reason, Hypothesis $2 \mathrm{~b}$ may be rejected for the MoBI and the IGNo treatment, but instead the preferred tax rates may be higher than the theory prediction made under the assumption of risk-neutral subjects. ${ }^{13}$ In particular, this could explain the occurrence, contrary to the theory prediction, of tax rates above zero in the IGNO treatment.

\footnotetext{
${ }^{13}$ Risk aversion is usually defined as a willingness to sacrifice expected income in exchange for a reduction in variance. In lotteries with small stakes (compared to the present value of lifetime income) such behavior cannot be explained well by the von-NeumannMorgenstern utility theory. As has been discussed also in the context of experimental
} 
In addition to the hypotheses on behavior within a given treatment, we can derive predictions on the impact of (perceived) social mobility on voting behavior and state hypotheses on differences of behavior across treatments. Let us first compare the RAND treatment to the BASE treatment. As the game in each round is exactly the same in these two treatments, from a theory point of view, behavior should not differ. Moreover, rounds are fully independent, and it is explained that the assignment of the wage rate is perfectly random. As subjects decide in a computer-simulated environment, they cannot establish a relation between their current choice and their coplayers' future choices. Thus, theory predicts that median tax rates in the BASE and the RAND treatment should be the same.

In the RAND treatment, however, subjects experience being in either of the roles, which is the only difference with respect to the BASE treatment. This "perceived mobility" may affect their behavior. If there is an effect of perceived mobility, then median tax rates should be lower in the RAND treatment than in the BASE treatment: if subjects are not strongly riskaverse, perceived mobility might result in a reaction similar to the one in the MoBI treatment. The perceived randomness might cause median voters to take the tax distortion effect better into account and to choose lower tax rates. $^{14}$

Hypothesis 3 (Rand vs. Base) a) In the RAND treatment, the median voter's choice of the tax rate is the same as in the BASE treatment.

b) (Counterhypothesis "perceived mobility effect") In the RAND treatment, the median voter's preferred tax rate is lower than in the BASE treatment.

economics, the von-Neumann-Morgenstern utility function is approximately linear for variations of lifetime incomes in a range of 20 Euro, suggesting locally risk-neutral behavior. Nevertheless, individuals seemingly exhibit risk aversion also with respect to such "small" lotteries in laboratory experiments, which can possibly be explained by rank-dependent utility and other deviations from expected utility.

${ }^{14}$ Changing the roles throughout the experiment might also lead to a better identification with the poor (and the rich) subject and therefore strengthen the median voter's "sense of justice/fairness". However, as co-players are simulated, such considerations are eliminated in our experiment. 
Past experience may help to identify effects of perceived mobility. In addition to a possible impact of the wage in the previous period on preferred tax rates, we can test whether perceived upward mobility (having become richer) or perceived downward mobility (having become poorer) affects behavior.

Next, we analyze the effect of actual social mobility by comparing the MOBI treatment to the BASE treatment. Here, we predict that, due to the possibility of obtaining a new wage in the same round, i.e., for the then fixed tax rate, the median voter's preferred tax rate is lower in the MoBI treatment than in the BASE treatment.

Hypothesis 4 (Mobi vs. Base) In the Moвi treatment, the median voter's preferred tax rate is lower than in the BASE treatment.

Strong risk aversion could diminish or even reverse this difference, because the median tax rate in the MовI treatment is higher the stronger the risk aversion. Moreover, risk aversion would imply that voters who have a high wage when choosing the tax rate would prefer a higher tax rate than voters with a high wage in the BASE treatment.

Finally, the IGNO treatment incorporates the effect of choices taking place behind the veil of ignorance. We expect preferred tax rates in the IGNo treatment to be lower than the median tax rates in the BASE treatment, since the consideration of the tax distortion effect should be stronger in the IGNO treatment, where in fact all voters are median voters.

Hypothesis 5 (Igno vs. Base) Preferred tax rates in the Igno treatment are lower than the median tax rates in the BASE treatment.

Preferred tax rates in the IGNO treatment may differ from predicted behavior, for a number of reasons. Risk aversion could matter, resulting in higher preferred tax rates. Also, choices could express maximin preferences which would result in preferred tax rates being equal to the optimal choice of the voter with the low wage. Further, if experience of previous rounds 
matters in the IGNO treatment, we may observe an impact of a subject's wage in the previous round.

\section{Estimation results}

To analyze the results of the experiment, we proceed in three steps. First, we estimate the subjects' choices of work effort as a function of tax rate and wage. Second, we identify the impact of the wage on preferred tax rates. Third, we examine in more detail the median voters' choices of the tax rate to determine the impact of social mobility on median tax rates. Before we turn to the estimation results, Table 2 provides an overview of the average preferred tax rates in the four treatments.

In Table 2, preferred tax rates of the different types of individuals are calculated both using all data and, in order to control for learning effects, using only data from late periods. ${ }^{15}$ If we focus on experienced behavior, in the BASE treatment the average preferred tax rate of voters with the low wage is equal to $65.1 \%$ and thus higher than the theory prediction of $50 \%$; the average choice of voters with the median tax rate is $32.8 \%$ and thus very close to the theoretically predicted choice of $33 \%$. The average preferred tax rate of voters with the high wage $(3.3 \%)$ is slightly higher than the predicted choice of $0 \%$. In the RAND treatment, average choices of individuals with low or high wage are similar to the BASE treatment, but the median tax rate, $20.5 \%$, is much lower, indicating that perceived mobility clearly seems to matter.

In the BASE and the RAND treatment, the tax rates strictly decrease with the wage. This is less obvious in the MoBI treatment. Here, in particular for the voters with medium or high wage, tax rates are higher than the theoretically predicted ones. Finally, in the IGno treatment, where voters

\footnotetext{
${ }^{15}$ Standard errors are adjusted using the "cluster"-option in STATA in order to control for non-independence of observation within the same group.
} 


\begin{tabular}{|c|c|c|c|c|c|c|c|c|}
\hline \multicolumn{9}{|c|}{ Average preferred tax rates } \\
\hline & \multicolumn{2}{|c|}{ BASE } & \multicolumn{2}{|c|}{ RAND } & \multicolumn{2}{|c|}{ MoBI } & \multicolumn{2}{|c|}{ IGNO } \\
\hline \multicolumn{9}{|c|}{ All periods } \\
\hline$w=0$ & $\begin{array}{c}\text { Pred. } \\
50\end{array}$ & $\begin{array}{l}\text { Obs. } \\
73.4 \\
(6.5)\end{array}$ & $\begin{array}{c}\text { Pred. } \\
50\end{array}$ & $\begin{array}{l}\text { Obs. } \\
63.9 \\
(6.6)\end{array}$ & $\begin{array}{c}\text { Pred. } \\
25\end{array}$ & $\begin{array}{l}\text { Obs. } \\
31.2 \\
(4.7)\end{array}$ & Pred. & $\begin{array}{c}\text { Obs. } \\
-\end{array}$ \\
\hline$w=3$ & 33 & $\begin{array}{l}34.6 \\
(4.5)\end{array}$ & 33 & $\begin{array}{l}23.9 \\
(2.8)\end{array}$ & 12.5 & $\begin{array}{l}22.2 \\
(3.2)\end{array}$ & & - \\
\hline$w=6$ & 0 & $\begin{array}{c}4.6 \\
(1.8)\end{array}$ & 0 & $\begin{array}{c}6.3 \\
(1.5)\end{array}$ & 0 & $\begin{array}{l}23.2 \\
(3.8)\end{array}$ & & - \\
\hline Avg. & & & & & & & 0 & $\begin{array}{l}19.9 \\
(3.1)\end{array}$ \\
\hline \multicolumn{9}{|c|}{ Experienced behavior } \\
\hline$w=0$ & $\begin{array}{c}\text { Pred. } \\
50\end{array}$ & $\begin{array}{l}\text { Obs. } \\
65.1 \\
(8.2)\end{array}$ & $\begin{array}{c}\text { Pred. } \\
50\end{array}$ & $\begin{array}{l}\text { Obs. } \\
67.4 \\
(6.7)\end{array}$ & $\begin{array}{c}\text { Pred. } \\
25\end{array}$ & $\begin{array}{l}\text { Obs. } \\
31.5 \\
(6.1)\end{array}$ & Pred. & Obs. \\
\hline$w=3$ & 33 & $\begin{array}{l}32.8 \\
(3.4)\end{array}$ & 33 & $\begin{array}{l}20.5 \\
(2.9)\end{array}$ & 12.5 & $\begin{array}{l}24.5 \\
(5.0)\end{array}$ & & \\
\hline$w=6$ & 0 & $\begin{array}{c}3.3 \\
(1.5)\end{array}$ & 0 & $\begin{array}{c}4.2 \\
(1.7)\end{array}$ & 0 & $\begin{array}{l}23.6 \\
(4.0)\end{array}$ & & \\
\hline Avg. & & & & & & & 0 & $\begin{array}{l}22.7 \\
(4.2)\end{array}$ \\
\hline
\end{tabular}

Note: Tax rates in percentage. Standard errors adjusted for clusters in parentheses. Experienced behavior: data from rounds $7-12$.

Table 2: Summary of experimental results 
did not know their wage when choosing the tax rate, the average preferred tax rate is $22.7 \%$ and hence clearly above zero, which would be the optimal choice of risk-neutral individuals.

The predictions on the preferred tax rates are based on the assumption that voters choose their payoff-maximizing effort in stage 2 of the game. Therefore, before examining the preferences on tax rates, we estimate the voters' work effort as a function of their wage and the implemented tax rate.

Work effort Theory predicts an effort choice equal to $x_{i t}=\left(1-\tau_{i t}\right) w_{i t}$, where $\tau_{i t}$ is the (known) tax rate chosen in group $i$ and round $t$; $w_{i t}$ is subject $i$ 's (known) wage in round $t$. Hence, $\left(1-\tau_{i t}\right) w_{i t}$ equals subject $i$ 's net wage. Let Treat be a vector that contains a variable equal to 1 for all observations and, in addition, dummy variables for the treatments RAND, MoBI, and IGNO. We estimate the work effort in stage 2 in a random effects model according to the equation

$$
x_{i t}=\boldsymbol{\alpha} \times \operatorname{TREAT}+\boldsymbol{\beta}\left(1-\tau_{i t}\right) w_{i t} \times \mathrm{TREAT}+\lambda_{i}+\varepsilon_{i t}
$$

where $\boldsymbol{\alpha}$ and $\boldsymbol{\beta}$ are vectors, and $\lambda_{i}$ is the individual specific random effect. By interacting the net wage with the vector TREAT, we allow for treatmentspecific intercepts.

Table 3 summarizes the results of two separate estimations of the work effort. The first estimation uses data from all periods, while the second estimation uses only observations from the second half of the experiment. The coefficients $\alpha_{1}$ to $\alpha_{4}$ measure the work effort chosen by individuals with a wage of zero, and the coefficients $\beta_{1}$ to $\beta_{4}$ determine the impact of the net wage on effort choices.

The constant $\alpha_{1}$ estimates the average work effort of voters with a wage of zero in the BASE treatment, which, although being small, is significantly positive in the first estimation, but no longer significantly different from zero if we account for learning effects (experienced behavior). The coefficients $\alpha_{2}$ 


\begin{tabular}{|c|c|c|}
\hline \multicolumn{3}{|l|}{ Work effort } \\
\hline \multicolumn{3}{|c|}{$\begin{array}{c}\text { Estimated equation } \\
x_{i t}=\boldsymbol{\alpha} \times \mathrm{TREAT}+\boldsymbol{\beta}\left(1-\tau_{i t}\right) w_{i t} \times \mathrm{TREAT}+\lambda_{i}+\varepsilon_{i t}\end{array}$} \\
\hline Estimation results & All periods & Experienced behavior \\
\hline$\alpha_{1}(\mathrm{CONSTANT})$ & $\begin{array}{l}0.252^{* *} \\
(0.117)\end{array}$ & $\begin{array}{c}0.146 \\
(0.133)\end{array}$ \\
\hline$\alpha_{2}(\mathrm{RAND})$ & $\begin{array}{c}0.047 \\
(0.150)\end{array}$ & $\begin{array}{c}0.079 \\
(0.171)\end{array}$ \\
\hline$\alpha_{3}(\mathrm{MoвI})$ & $\begin{array}{l}-0.135 \\
(0.152)\end{array}$ & $\begin{array}{l}-0.032 \\
(0.176)\end{array}$ \\
\hline$\alpha_{4}(\mathrm{IGNO})$ & $\begin{array}{c}0.007 \\
(0.151)\end{array}$ & $\begin{array}{c}0.026 \\
(0.171)\end{array}$ \\
\hline$\beta_{1}\left(\left(1-\tau_{i t}\right) w_{i t}\right)$ & $\begin{array}{l}0.965^{* * *} \\
(0.042)\end{array}$ & $\begin{array}{l}0.991^{* * *} \\
(0.048)\end{array}$ \\
\hline$\beta_{2}\left(\left(1-\tau_{i t}\right) w_{i t} \times \mathrm{RAND}\right)$ & $\begin{array}{c}0.060 \\
(0.048)\end{array}$ & $\begin{array}{c}0.004 \\
(0.057)\end{array}$ \\
\hline$\beta_{3}\left(\left(1-\tau_{i t}\right) w_{i t} \times\right.$ MoBI $)$ & $\begin{array}{c}0.012 \\
(0.047)\end{array}$ & $\begin{array}{l}-0.014 \\
(0.056)\end{array}$ \\
\hline$\beta_{4}\left(\left(1-\tau_{i t}\right) w_{i t} \times\right.$ IGNO $)$ & $\begin{array}{l}-0.035 \\
(0.045)\end{array}$ & $\begin{array}{l}-0.052 \\
(0.053)\end{array}$ \\
\hline$R^{2}$ (overall) & 0.863 & 0.884 \\
\hline$N$ & 1152 & 576 \\
\hline
\end{tabular}

Note: ${ }^{* * *}\left({ }^{* *}\right)$ significant at $1 \%(5 \%)$. Standard errors in parentheses. Experienced behavior: data from rounds 7-12.

Table 3: Estimation results for effort choices 


\begin{tabular}{lcc}
\hline \hline Work effort & \\
\hline \multicolumn{3}{c}{ Estimated equation } \\
\multicolumn{3}{c}{$x_{i t}=\boldsymbol{\alpha} \times$ TREAT $+\boldsymbol{\beta}\left(1-\tau_{i t}\right) w_{i t} \times \mathrm{TREAT}+\lambda_{i}+\varepsilon_{i t}$} \\
\hline Hypothesis testing & All periods & Experienced behavior \\
\hline$H_{0}: \beta_{1}=1$ & $p=0.405$ & $p=0.854$ \\
$H_{0}: \beta_{1}+\beta_{2}=1$ & $p=0.314$ & $p=0.889$ \\
$H_{0}: \beta_{1}+\beta_{3}=1$ & $p=0.289$ & $p=0.426$ \\
$H_{0}: \beta_{1}+\beta_{4}=1$ & $\mathbf{p}<\mathbf{0 . 0 0 1}$ & $\mathbf{p}=\mathbf{0 . 0 0 7}$ \\
\hline$H_{0}: \alpha_{1}+\alpha_{2}=0$ & $\mathbf{p}=\mathbf{0 . 0 0 2}$ & $\mathbf{p}=\mathbf{0 . 0 3 6}$ \\
$H_{0}: \alpha_{1}+\alpha_{3}=0$ & $p=0.229$ & $p=0.322$ \\
$H_{0}: \alpha_{1}+\alpha_{4}=0$ & $\mathbf{p}=\mathbf{0 . 0 0 7}$ & $p=0.113$ \\
\hline \hline
\end{tabular}

Note: Experienced behavior: data from rounds 7-12. $H_{O}$ tested by means of two-tailed Wald tests.

Table 4: Hypothesis testing for effort choices

to $\alpha_{4}$ control for treatment differences with respect to the BASE treatment; none of these coefficients is significantly different from zero.

More importantly, there is a strictly positive impact of the net wage on work effort in the BASE treatment (measured by $\beta_{1}$ ). Again, we do not find treatment effects (no significance of $\beta_{2}$ to $\beta_{4}$ ). Thus, the choice of work effort does not differ across treatments. The results in Table 3 already show that the impact of an increase in the net wage is close to one, which would be the theoretically predicted impact. To test whether the observed behavior is exactly in line with the theory prediction (Hypothesis 1), we perform additional tests summarized in Table 4.

The first set of tests in Table 4 demonstrates that, in all but the IGNO treatment, we cannot reject the hypothesis that the marginal effect of the net wage on work effort is equal to one. Even in the IGNO treatment this impact is close to one. Second, the test results show that, in the RAND treatment (and in the IGNo treatment considering all periods), subjects with a wage of zero have, on average, chosen a significantly positive work effort (test in 
rows 5 and 7 in Table 4). These "mistakes" do not occur very often; in $90 \%$ of the cases, a work effort of zero has been chosen, and, under experienced behavior, 21 out of the 24 subjects in the RAND treatment chose zero effort whenever they were assigned the low wage.

Result 1 The voters' choices of the work effort are almost perfectly in line with the theory prediction (Hypothesis 1). We do not find statistically significant differences among treatments.

The fact that observed effort choices are very close to the theoretically predicted choices is an important finding. It suggests that, in the absence of other-regarding preferences, voters correctly anticipate the distortionary effects of redistributive taxes.

Preferred tax rate To estimate the subjects' preferred tax rates, we use a random effects estimation similar to the one above. We estimate the preferred tax rate $\tau_{i t}$ of subject $i$ in round $t$ as a function of the wage $w_{i t}$ and interaction terms of $w_{i t}$ with dummies for the different treatments. Since theory predicts an individual's preferred tax rate to be a non-linear function of the individual's wage rate, we include the squared wage rate $w_{i t}^{2}$ into the regression and estimate subject $i$ 's preferred tax rate $\tau_{i t}$ in period $t$ as

$$
\tau_{i t}=\boldsymbol{\alpha} \times \mathrm{TREAT}+\boldsymbol{\beta} w_{i t} \times \mathrm{TREAT}+\boldsymbol{\gamma} w_{i t}^{2} \times \mathrm{TREAT}+\lambda_{i}+\varepsilon_{i t}
$$

where the vector TREAT again contains a variable equal to 1 for all observations as well as treatment dummies for RAnd, MoBI and Igno. Again, $\lambda_{i}$ corresponds to the individual specific effect.

Table 5 presents results for two estimations, the first using all data and the second using data only from rounds with experience. Similar to the regression of effort choices, the coefficients $\alpha_{1}$ to $\alpha_{4}$ determine the voters' average preferred tax rate in case of $w=0$, and $\beta_{1}$ to $\beta_{3}$ together with $\gamma_{1}$ to $\gamma_{3}$ capture the impact of the wage on the voters' choices. As in the IGNo 


\begin{tabular}{|c|c|c|}
\hline \multicolumn{3}{|c|}{ Preferred tax rate } \\
\hline \multicolumn{3}{|c|}{$\begin{array}{l}\text { Estimated equation } \\
\boldsymbol{\beta} w_{i t} \times \mathrm{TREAT}+\boldsymbol{\gamma} w_{i+}^{2} \times \mathrm{TREAT}+\lambda_{i}+\varepsilon_{i t}\end{array}$} \\
\hline Estimation results & All periods & Experienced behavior \\
\hline$\alpha_{1}(\operatorname{CONSTANT})$ & $\begin{array}{l}73.365^{* * *} \\
(5.053)\end{array}$ & $\begin{array}{c}65.104^{* * *} \\
(6.079)\end{array}$ \\
\hline$\alpha_{2}(\mathrm{RAND})$ & $\begin{array}{r}-10.573^{*} \\
(6.054)\end{array}$ & $\begin{array}{l}1.993 \\
(7.320)\end{array}$ \\
\hline$\alpha_{3}(\mathrm{MoBI})$ & $\begin{array}{c}-42.310^{* * *} \\
(6.071)\end{array}$ & $\begin{array}{c}-34.850^{* * *} \\
(7.375)\end{array}$ \\
\hline$\alpha_{4}(\mathrm{IGNO})$ & $\begin{array}{c}-53.458^{* * *} \\
(5.835)\end{array}$ & $\begin{array}{l}-42.410^{* * *} \\
(7.020)\end{array}$ \\
\hline$\beta_{1}\left(w_{i t}\right)$ & $\begin{array}{c}-14.392^{* * *} \\
(4.294)\end{array}$ & $\begin{array}{c}-11.274^{* *} \\
(5.166)\end{array}$ \\
\hline$\beta_{2}\left(w_{i t} \times \mathrm{RAND}\right)$ & $\begin{array}{l}-1.745 \\
(4.646)\end{array}$ & $\begin{array}{l}-6.684 \\
(5.711)\end{array}$ \\
\hline$\beta_{3}\left(w_{i t} \times\right.$ MовI $)$ & $\begin{array}{l}10.326^{* *} \\
(4.664)\end{array}$ & $\begin{array}{l}8.980 \\
(5.758)\end{array}$ \\
\hline$\beta_{4}\left(w_{i t} \times \mathrm{IGNO}\right)$ & - & - \\
\hline$\gamma_{1}\left(w_{i t}^{2}\right)$ & $\begin{array}{l}0.487 \\
(0.688)\end{array}$ & $\begin{array}{c}0.163 \\
(0.827)\end{array}$ \\
\hline$\gamma_{2}\left(w_{i t}^{2} \times \mathrm{RAND}\right)$ & $\begin{array}{c}0.647 \\
(0.744)\end{array}$ & $\begin{array}{c}0.996 \\
(0.917)\end{array}$ \\
\hline$\gamma_{3}\left(w_{i t}^{2} \times\right.$ МовІ $)$ & $\begin{array}{l}-0.041 \\
(0.747)\end{array}$ & $\begin{array}{c}0.052 \\
(0.922)\end{array}$ \\
\hline$\gamma_{4}\left(w_{i t}^{2} \times \mathrm{IGNO}\right)$ & - & - \\
\hline$R^{2}$ (overall) & 0.421 & 0.399 \\
\hline$N$ & 1152 & 576 \\
\hline
\end{tabular}

Note: Tax rates in percentage. ${ }^{* * *}\left({ }^{* *},{ }^{*}\right)$ significant at $1 \%(5 \%, 10 \%)$. Standard errors in parentheses. Experienced behavior: data from rounds 7-12.

Table 5: Regression results for preferred tax rates 
treatment there is no wage effect, $\alpha_{1}+\alpha_{4}$ identifies the average preferred tax rate in this treatment. ${ }^{16}$

More in detail, $\alpha_{1}$ estimates the average tax rate preferred by voters with a low wage in the BASE treatment, and $\alpha_{2}, \alpha_{3}$ and $\alpha_{4}$ identify deviations for the other three treatments. The choices of the low-wage types in the RAND treatment are significantly different from the BASE treatment only if we consider all periods (compare $\alpha_{2}$ ). In the MoBI treatment, however, voters with the low wage choose a much lower tax rate than in the BASE treatment $\left(\alpha_{3}\right)$. For the IGNo treatment, the sum of $\alpha_{1}$ and $\alpha_{4}$ measures the average preferred tax rate (over all types), which is equal to $19.9 \%$ considering all periods and $22.7 \%$ focusing on experienced behavior. Both this average tax rate in the IGNO treatment and the preferred tax rates of low-wage types in the other treatments are higher than predicted by theory (compare Table 2).

Now consider the impact of the wage. As $\beta_{1}$ shows, there is a significantly negative effect of the wage rate on preferred tax rates in the BASE treatment. Moreover, $\beta_{2}$ and $\gamma_{2}$ indicate that there is no significant difference between the BASE and RAND treatments. In the MoBI treatment, however, the marginal effect of the wage on tax rate choices is significantly weaker, at least if we consider all periods $\left(\beta_{3}\right) \cdot{ }^{17}$

Table 6 tests whether the impact of the wage in treatments RAND and MOBI is different from zero. In the RAND treatment, there is a significant impact of both $w_{i t}$ and $w_{i t}^{2}$ on preferred tax rates (rows 1 and 3 in Table 6 ). In fact, here the preferred tax rate is a decreasing and convex function of the wage. $^{18}$ In the МовI treatment, the impact of $w_{i t}$ is significantly negative only if we consider all periods (row 2 in Table 6 ), and there is no significant

\footnotetext{
${ }^{16}$ Since in the IGNO treatment subjects don't know their wage when they choose the tax rate, the interaction terms with the wage are omitted.

${ }^{17}$ In another estimation, we included the subjects' wage in the previous round $\left(w_{i, t-1}\right)$ interacted with treatment dummies into the estimation. None of these variables has a significant impact (with the exception of $w_{i, t-1} \times \mathrm{R}$ AND which is significantly positive at the $10 \%$-level if we consider all periods); all results on the other coefficients remain unchanged.

${ }^{18}$ The slope is equal to $\beta_{2}+2 \gamma_{2} w$, which is indeed strictly decreasing for all $w \in[0,6]$.
} 


\begin{tabular}{lcc}
\hline \hline \multicolumn{3}{l}{ Preferred tax rate } \\
\hline \multicolumn{3}{c}{ Estimated equation } \\
$\tau_{i t}=\boldsymbol{\alpha} \times$ TREAT $+\boldsymbol{\beta} w_{i t} \times$ TREAT $+\gamma w_{i t}^{2} \times$ TREAT $+\lambda_{i}+\varepsilon_{i t}$ \\
\hline Hypothesis testing & All periods & Experienced behavior \\
$H_{0}: \beta_{1}+\beta_{2}=0$ & $\mathbf{p}<\mathbf{0 . 0 0 1}$ & $\mathbf{p}<\mathbf{0 . 0 0 1}$ \\
$H_{0}: \beta_{1}+\beta_{3}=0$ & $\mathbf{p}=\mathbf{0 . 0 2 6}$ & $p=0.367$ \\
\hline$H_{0}: \gamma_{1}+\gamma_{2}=0$ & $\mathbf{p}<\mathbf{0 . 0 0 1}$ & $\mathbf{p}=\mathbf{0 . 0 0 4}$ \\
$H_{0}: \gamma_{1}+\gamma_{3}=0$ & $p=0.126$ & $p=0.598$ \\
\hline \hline
\end{tabular}

Note: Experienced behavior: data from rounds $7-12 . H_{O}$ tested by means of two-tailed Wald tests.

Table 6: Hypothesis testing for preferred tax rates

effect of $w_{i t}^{2}$ (row 4$)$. The average preferred tax rate of the high-wage type is almost the same as the average preferred tax rate of the medium-wage type (compare Table 2). ${ }^{19}$ This may be explained by the relatively large degree of mobility (wages reassigned with probability 75\%), as average tax rates are similar to the average tax rates in the IGNo treatment.

Result 2 Preferred tax rates are strictly decreasing in the wage rate in treatments BASE and RAND, confirming Hypothesis 2a). In the MoBI treatment, the effect of the wage rate on preferred tax rates is only weak.

To test Hypothesis $2 \mathrm{~b}$ on the median voters' preferred tax rates and Hypotheses 3-5 on intra-treatment effects, we run a further regression including only median voters' choices. For the RAND and the MoBI treatments, we model past mobility by adding a variable containing the difference between actual wage and previous wage, $\Delta w_{i t}=w_{i t}-w_{i, t-1}$, interacted with treatment dummies. If $\Delta w_{i t}$ is positive, this expresses upward mobility (the individual has become richer), and $\Delta w_{i t}<0$ expresses downward mobility. For the IGNO treatment, where subjects do not know their actual wage, we include

\footnotetext{
${ }^{19}$ Controlling for outliers, this also holds for the choices of voters with a low wage.
} 
$w_{i, t-1}$ into the estimation. Here, contrary to the other three treatments, all observations are included in the estimation, since all voters can be considered as median voters.

We estimate a linear regression of the form

$\tau_{i t}=\boldsymbol{\alpha} \times \mathrm{TREAT}+\beta_{2} \Delta w_{i t} \times \mathrm{RAND}+\beta_{3} \Delta w_{i t} \times \mathrm{MOBI}+\beta_{4} w_{i, t-1} \times \mathrm{IGNO}+\varepsilon_{i t}$

where TREAT contains a variable equal to 1 for all observations as well as dummies for RAND, MoBI and IGno. ${ }^{20}$ The estimation results are shown in the first part of Table 7, while the second part of Table 7 tests whether median voters' behavior in the four treatments is in line with the theory prediction.

First, consider the estimation results in the first part of Table 7 . In the BASE treatment, the average preferred tax rate of the median voter (measured by $\alpha_{1}$ ) is equal to $35.2 \%$ (32.75\% if we consider only experienced behavior) and therefore close to the predicted choice of $33 \%$. Perhaps surprisingly, however, there is a significant treatment effect $\left(\alpha_{2}\right)$ if we introduce perceived social mobility: even if the game is exactly the same in each round and rounds are clearly independent, median tax rates in the RAND treatment are about $12 \%$ lower than in the BASE treatment.

For the treatment effect in the MoBI treatment (coefficient $\alpha_{3}$ ), learning does play a role. The point estimate as well as the significance level differ in the two estimations in Table 7; overall, actual social mobility leads to tax rates that are lower than in the BASE treatment. The same is true for the IGNO treatment where learning seems to be important and tax rates are about $15 \%$ (10\% under experienced behavior) lower than in the BASE

\footnotetext{
${ }^{20} \mathrm{We}$ control for possible non-independence of observations by clustering the standard errors on individual level (using the cluster option provided by STATA). If we estimate a random effects model, the results are similar, but partly depend on whether or not we include the observations of the IGNO treatment into the estimation; this suggests that the assumption of the random effects model on the variance of the individual specific effects may not hold.
} 


\begin{tabular}{|c|c|c|}
\hline \multicolumn{3}{|l|}{ Median tax rate } \\
\hline \multicolumn{3}{|c|}{$\begin{array}{c}\text { Estimated equation } \\
\tau_{i t}=\alpha \times \mathrm{TREAT}+\beta_{2} \Delta w_{i t} \times \mathrm{RAND}+\beta_{3} \Delta w_{i t} \times \mathrm{MOBI}+\beta_{4} w_{i, t-1} \times \mathrm{IGNO}+\varepsilon_{i t}\end{array}$} \\
\hline Estimation results & All periods & Experienced behavior \\
\hline$\alpha_{1}(\mathrm{CONSTANT})$ & $\begin{array}{l}35.239^{* * *} \\
(4.667)\end{array}$ & $\begin{array}{l}32.750^{* * *} \\
(3.430)\end{array}$ \\
\hline$\alpha_{2}(\mathrm{RAND})$ & $\begin{array}{c}-11.630^{* *} \\
(5.507)\end{array}$ & $\begin{array}{l}-12.264^{* * *} \\
(4.526)\end{array}$ \\
\hline$\alpha_{3}(\mathrm{MoBI})$ & $\begin{array}{c}-14.335^{* *} \\
(5.458)\end{array}$ & $\begin{array}{l}-9.121 \\
(5.544)\end{array}$ \\
\hline$\alpha_{4}(\mathrm{IGNO})$ & $\begin{array}{l}-15.671^{* * *} \\
(5.379)\end{array}$ & $\begin{array}{c}-10.918^{* *} \\
(5.104)\end{array}$ \\
\hline$\beta_{2}\left(\Delta w_{i t} \times \mathrm{RAND}\right)$ & $\begin{array}{l}-0.942 \\
(0.809)\end{array}$ & $\begin{array}{l}-0.046 \\
(1.025)\end{array}$ \\
\hline$\beta_{3}\left(\Delta w_{i t} \times\right.$ MoBI $)$ & $\begin{array}{l}-1.428 \\
(1.038)\end{array}$ & $\begin{array}{l}-1.162 \\
(1.720)\end{array}$ \\
\hline$\beta_{4}\left(w_{i, t-1} \times \operatorname{IGNO}\right)$ & $\begin{array}{c}0.232 \\
(0.583)\end{array}$ & $\begin{array}{c}0.282 \\
(0.602)\end{array}$ \\
\hline$R^{2}$ (overall) & 0.063 & 0.032 \\
\hline$N$ & 516 & 281 \\
\hline
\end{tabular}

\begin{tabular}{lcc} 
Hypothesis testing & All periods & Experienced behavior \\
\hline$H_{0}: \alpha_{1}=33$ & $p=0.633$ & $p=0.942$ \\
$H_{0}: \alpha_{1}+\alpha_{2}=33$ & $\mathbf{p}=\mathbf{0 . 0 0 2}$ & $\mathbf{p}<\mathbf{0 . 0 0 1}$ \\
$H_{0}: \alpha_{1}+\alpha_{3}=12$ & $\mathbf{p}=\mathbf{0 . 0 0 2}$ & $\mathbf{p}=\mathbf{0 . 0 0 9}$ \\
$H_{0}: \alpha_{1}+\alpha_{4}=0$ & $\mathbf{p}<\mathbf{0 . 0 0 1}$ & $\mathbf{p}<\mathbf{0 . 0 0 1}$ \\
\hline$H_{0}: \alpha_{2}=\alpha_{3}$ & $p=0.508$ & $p=0.552$ \\
\hline \hline
\end{tabular}

Note: Tax rates in percentage. ${ }^{* * *}\left({ }^{* *}\right)$ significant at $1 \%(5 \%)$. Standard errors in parentheses. Experienced behavior: data from rounds 7-12. $H_{O}$ tested by means of two-tailed Wald tests.

Table 7: Regression results and hypothesis testing for median tax rates 


\section{treatment.}

Second, let us examine in more detail the point estimates of the median voter's preferred tax rate. Rows 1-4 in the second part of Table 7 report the results of testing Hypothesis $2 \mathrm{~b}$ on the exact values of the observed choices. First, we cannot reject that $\alpha_{1}=33$, that is, we cannot reject that median voters in the BASE treatment behave exactly according to the theory. Implementing the logic of Meltzer and Richard (1981) in its purest form, we observe median tax rates that are fully in line with the theory. Adding different notions of social mobility, however, leads to significantly different voting behavior. This holds even if there is no actual social mobility between tax rate choice and earnings decisions: in the RAND treatment, median tax rates are significantly lower than predicted. This is one of the key results of our paper, and we discuss its implication in the conclusion.

In the MoBI and the IGno treatment, the median voter's preferred tax rate is significantly higher than the theory prediction. One explanation for this result could be risk aversion, since in the latter two treatments the choice takes place under uncertainty. ${ }^{21}$

Result 3 Hypothesis $2 b$ on median tax rates cannot be rejected for the BASE treatment. In the RAND, MOBI, and the IGNO treatment, median tax rates significantly differ from the theory prediction.

As shown in the estimation results in Table 7, the perception of social mobility seems to have an important impact on the voters' decisions. Since perceived social mobility leads to lower tax rates, perceived downward mobility does not cause an upward adjustment of tax rates, but instead the

\footnotetext{
${ }^{21}$ We also run non-parametric tests on group means (being defined as average chosen tax rate within a group, i.e. per subject). The results are exactly the same: we cannot reject that the median tax rate in the BASE treatment is equal to $33 \%$, but we can reject in the other treatments that subjects behave exactly according to theory. Moreover, the tests suggest that preferred tax rates of voters with low or high wage differ from the exact theory prediction, with two exceptions: preferred tax rates of high-wage types in the MoBI treatment and in the BASE treatment do not significantly differ from the theory prediction (where in the latter case this only holds under experienced behavior).
} 
perception of upward mobility dominates. With respect to past experience measured by $\Delta w_{i t}$, the estimated coefficient $\beta_{2}$ is negative, implying that subjects that have become richer tend to choose lower tax rates. This coefficient, however, is not significantly different from zero. Thus, in addition to the negative treatment effect of the RAND treatment, there is no further significant impact of past experience.

Result 4 The median tax rates in the RAND treatment are significantly lower than in the BASE treatment. This rejects Hypothesis $3 a$ and provides evidence in favor of Hypothesis $3 b$ on the role of perceived social mobility.

As discussed above, for the MoBI treatment there is a negative treatment effect only if we include all periods into the estimation. Nevertheless, average preferred tax rates of the median voter are considerably lower than in the BASE treatment. Introducing actual social mobility within a round does affect average choices, although the variance of preferred tax rates is large. Interestingly, comparing the treatment effects of the MOBI and the RAND treatment, we do not find a significant difference (last row in Table 7). In the RAND treatment, there is only perceived social mobility (possibly different wages experienced in the past, or anticipated for rounds some time in the future) whereas in the MoBI treatment, actual social mobility is added: subjects obtained a new wage in each round, which could again change within the round, after the tax rate was chosen. There is, however, no additional effect of adding actual social mobility to perceived social mobility, suggesting that the entire effect of social mobility has already been captured in the RAND treatment. ${ }^{22}$ While the lower preferred taxes in case of actual mobility are in line with payoff-maximizing rational behavior, the similarity of the effects of perceived mobility (RAND) and actual mobility (MOBI) is more

\footnotetext{
${ }^{22}$ Again, we run non-parametric tests on group means to compare average behavior across treatments. All results are confirmed. We find a significant treatment effect of both the RAND and the MoBi treatment, but we do not find a significant difference between median tax rates in the RAND and the MOBI treatment.
} 
difficult to interpret. Subjects may follow a simple heuristic ("intuition", "gut feeling") that tells them that lower tax rates are better for them in the presence of income mobility. Such a heuristic as a choice rule performs very well compared to a full optimization program in an empirical environment in which the sequencing of changes of income and tax rates typically is not as deterministic and less clear-cut than in the two treatments. Subjects may have adopted this heuristic in such a more natural environment. Instead of solving the specific optimization problem at hand, they may have used this heuristic in all instances of income mobility. ${ }^{23}$

Result 5 The median tax rates in the MоBI treatment are (weakly) significantly lower than in the BASE treatment, confirming Hypothesis 4. Median tax rates in the RAND and the MOBI treatment do not differ significantly.

Finally, we find that, behind the veil of ignorance, choices of the tax rate are significantly lower than in the BASE treatment. Thus, voters take into account the tax distortion effect. Tax rates are, however, also significantly higher than predicted by theory. Furthermore, we do not find a significant impact of the wage in the previous round $\left(\beta_{4}\right)$. We will conclude the empirical analysis of our results by examining in more detail the choices made behind the veil of ignorance.

Figure 1 shows the distribution of tax rates that each single individual in the IGNO treatment chose on average. (Recall that in total there are 24 subjects in this treatment.) An interesting pattern evolves in the histogram. It basically identifies three groups of subjects. A first group, of about $42 \%$ of the subjects, chose on average a tax rate below $10 \%$, the mean of this group being a tax rate of $4.78 \%$. A second group, involving about $54 \%$ of the subjects, chose a tax rate between $20 \%$ and $40 \%$. The average choice within

\footnotetext{
${ }^{23}$ Work by psychologists (see, e.g., Gigerenzer 2007) suggests that heuristics play a major role governing human behavior. Whether or not heuristics or some other factors explain the similarity in tax rate choices in the two mobility treatments would have to be explored in a separate analysis.
} 


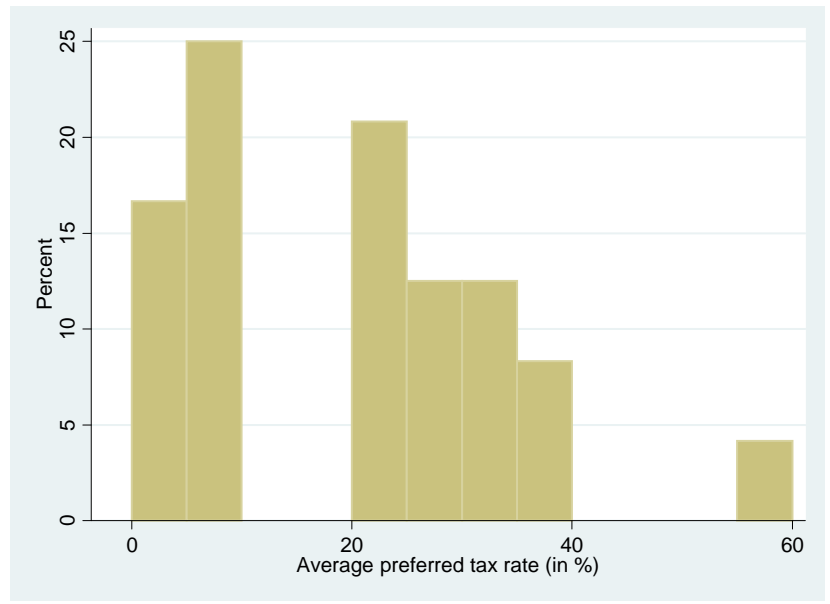

Figure 1: Distribution of average tax rates in the IGNO treatment

this group is equal to $28.46 \%$. A third group which, in fact, consists of only one subject, chose an average tax rate of $60 \%$.

The choice of the first group is, although positive (4.78\%), close to the theory prediction of a tax rate of zero. ${ }^{24}$ Thus, the decisions of this group of subjects take into account the tax distortion effects; risk aversion does not affect this choice of the tax rate. The majority of subjects, however, chose a higher tax rate which is between the median voters' choice of the tax rate in the BASE and the RAND treatment. Only one subject chose a much higher tax rate; this choice is similar to the preferred tax rates of voters with the low wage in the BASE and the RAND treatment and could thus be considered as expressing maximin preferences.

Another interpretation of the behavior of the second group can be given if one remembers the situation in which individuals decide: they have to choose a tax rate knowing that they will end up with either a low, a medium, or a high wage. If they knew their wage, they would optimally choose a tax rate of $50 \%, 33 \%$, and $0 \%$, respectively. Their actual choice under uncertainty

\footnotetext{
${ }^{24}$ As shown in Table 2 , in the BASE treatment individuals with a high wage chose a similar tax rate (on average $4.6 \%$ ) even if a zero tax rate is predicted by theory.
} 
( $28.46 \%$ on average) is almost exactly equal to the average of the three potentially optimal tax rates (which would be $27.67 \%$ ). This may suggest that a large part of individuals employs a simple - but wrong - heuristic when deciding on the tax rate: they simply choose the average of the tax rates they would prefer in the three possible outcomes of the wage assignment.

Result 6 The average preferred tax rate in the IGNO treatment is lower than in the BASE treatment, but higher than theoretically predicted. Two different types of behavior can be identified: one part of the subjects choose tax rates close to the theory prediction, and another part of the subjects choose tax rates close to the average of the tax rates that would be optimal if subjects knew their wage.

\section{Conclusion}

The seminal theory of Meltzer and Richard (1981) provides an important concept for redistributive taxation in a context of political decision-making: material interests determine the choice of redistributive taxes, taking into account incentive effects of higher taxes on individual work effort. To identify this logic in empirical studies, however, is difficult, due to the many factors that may cloud the picture and that cannot easily be controlled for. The laboratory creates an environment in which most of these additional factors can be removed or controlled for. Indeed, implementing the Meltzer-Richard logic in its purest form in a laboratory experiment shows that the individuals understand the consequences of decisions on redistributive taxation and vote in line with their material interest. In our baseline treatment, where the individuals' productivity was known and fixed throughout the experiment, voting decisions were driven by individual productivity and the subjects correctly anticipated the incentive effects of higher taxes. The median voter's choice of the tax rate was almost perfectly in line with the theory prediction of Meltzer and Richard. 
As soon as factors other than individual productivity become relevant, the voters' choices may change. In three further treatments, we examined the consequences of individual social mobility as one of the very important factors that influence preferences for redistribution and that can be identified in the laboratory. We considered three different regimes of individual income mobility. In the first regime, the setup in each single round was exactly as in the baseline treatment implementing Meltzer-Richard, with the only exception that in each round individual productivity was randomly assigned and thus changed during the experiment. With this "perceived social mobility", material interest still determined the choices of redistributive tax rates. However, even though the rounds were completely independent, the median voter's tax rate was significantly lower than in the baseline treatment, suggesting that perceived social mobility - i.e. a history of changes in own wage in the past and prospects of changes in own wage in the future causes preferred tax rates to be lower.

In a second mobility regime, we added actual social mobility: when deciding on redistributive taxation, the individuals only had an imperfect signal about their actual productivity in a given round and learned their actual productivity only after the tax rate was chosen. As a consequence of this income mobility, median tax rates were lower than in the baseline treatment, but they did not differ from the first mobility regime where productivity only fluctuated between rounds.

In the third mobility regime, individuals did not know their income position when deciding on taxation. Two major types of behavior emerged: one part of the individuals chose tax rates close to the theory prediction, taking into account disincentive effects from taxation; a second group of subjects chose tax rates close to the average of potentially optimal tax rates.

In all treatments, we embedded the subjects in an environment where the co-players were simulated by computers. This largely removed the individuals' strategic uncertainty regarding the distortionary effect of taxation on 
their co-players' work effort and enables us to focus on choices of redistributive taxes. More importantly, it creates an environment that can identify the driving forces in the Meltzer-Richard framework and the role of social mobility in a framework in which other-regarding preferences or social preferences have no relevance. As a key result, we find that both perceived and actual individual social mobility matter for the choice of tax rates and induce the median wage earners to choose lower taxes. These results would be in line with some of the theories of other-regarding preferences or with preferences about an equitable income distribution in a society. Interestingly, however, these effects emerge here even though other-regarding preferences or social preferences can be ruled out as possible explanations; there is no room for social preferences if the society consists of only one real player, who is teamed up with two computerized players. These observations are important for the interpretation of earlier findings on preferences for redistribution and social mobility. The results hint at possible different explanations for these findings.

\section{References}

[1] Bénabou, Roland, 2000. Unequal societies: income distribution and the social contract. American Economic Review 90(1), 96-129.

[2] Bénabou, Roland, and Efe A. Ok, 2001. Social mobility and the demand for redistribution: The POUM hypothesis. Quarterly Journal of Economics 116(2), 447-487.

[3] Durante, Ruben, and Louis Putterman, 2009. Preferences for redistribution and perceptions of fairness: an experimental study. Unpublished manuscript.

[4] Feddersen, Timothy, Sean Gailmard, and Alvaro Sandroni, 2009. Moral bias in large elections: theory and experimental evidence. American Political Science Review 103(2), 175-192. 
[5] Fehr, Ernst, and Klaus M. Schmidt, 1999. A theory of fairness, competition, and cooperation. Quarterly Journal of Economics 114(3), 817-868.

[6] Fershtman, Chaim, Kevin M. Murphy, and Yoram Weiss, 1996. Social status, education, and growth. Journal of Political Economy 104(1), 108-132.

[7] Fischbacher, Urs, 2007. z-Tree: Zurich Toolbox for Ready-made Economic Experiments. Experimental Economics 10(2), 171-178.

[8] Frank, Robert H., 1984. Interdependent preferences and the competitive wage structure. Rand Journal of Economics 15(4), 510-520.

[9] Frank, Robert H., 1985. The demand for unobservable and other nonpositional goods. American Economic Review 75(1), 101-116.

[10] Gigerenzer, Gerd, 2007, Gut Feelings: the Intelligence of the Unconscious, Penguin Books.

[11] Glazer, Amihai, 1987. A new theory of voting: why vote when millions of others do. Theory and Decision 22(3), 257-270.

[12] Glazer, Amihai, and Kai A. Konrad, 1996. A signaling explanation for charity. American Economic Review 86(4), 1019-1028.

[13] Greiner, Ben, 2004. An Online Recruitment System for Economic Experiments. In: Kurt Kremer, Volker Macho (Eds.): Forschung und wissenschaftliches Rechnen 2003. GWDG Bericht 63, Göttingen: Ges. für Wiss. Datenverarbeitung, 79-93.

[14] Hochman, Harold M., and James D. Rodgers, 1969. Pareto optimal redistribution. American Economic Review 59(4), 542-557.

[15] Huck, Steffen, and Kai A. Konrad, 2005. Moral cost, commitment, and committee size. Journal of Institutional and Theoretical Economics 161(4), 575-588. 
[16] Isaksson, Ann-Sofie, and Annika Lindskog, 2009. Preferences for redistribution - a country comparison of fairness judgements. Journal of Economic Behavior \& Organization 72(3), 884-902.

[17] Krawczyk, Michal, 2010. A glimpse through the veil of ignorance: equality of opportunity and support for redistribution. Journal of Public Economics 94, 131-141.

[18] Krusell, Per, and José-Víctor Ríos-Rull, 1999. On the size of U.S. government: political economy in the neoclassical growth model. American Economic Review 89(5), 1156-1181.

[19] Meltzer, Allan H., and Scott F. Richard, 1981. A rational theory of the size of government. Journal of Political Economy 89(5), 914-927.

[20] Moene, Karl Ove, and Michael Wallerstein, 2001. Inequality, social insurance, and redistribution. American Political Science Review 95(4), 859-874.

[21] Moene, Karl Ove, and Michael Wallerstein, 2003. Earnings inequality and welfare spending: a disaggregated analysis. World Politics 55(4), 485-516.

[22] Neustadt, Ilja, and Peter Zweifel, 2009. Social mobility and preferences for income redistribution: evidence from a discrete choice experiment. Socioeconomic Institute, University of Zurich, Working Paper No. 0909.

[23] Piketty, Thomas, 1995. Social mobility and redistributive politics. Quarterly Journal of Economics 110(3), 551-584.

[24] Rehm, Philipp, 2009. Risks and redistribution: an individual-level analysis. Comparative Political Studies 42(7), 855-881. 
[25] Shayo, Moses, 2006. Social identity and redistributive politics. In: Mark Gradstein and Kai A. Konrad (Eds.): Institutions and Norms in Economic Development. MIT Press, 201-225.

[26] Shayo, Moses, 2009. A model of social identity with an application to political economy: nation, class, and redistribution. American Political Science Review 103(2), 147-174.

[27] Tyran, Jean-Robert, and Rupert Sausgruber, 2006. A little fairness may induce a lot of redistribution in democracy. European Economic Review 50(2), 469-485.

[28] Varian, Hal R., 1980. Redistributive taxation as social insurance. Journal of Public Economics 14(1), 49-68.

[29] Veblen, Thorstein, 1899. The Theory of the Leisure Class: an Economic Study of Institutions. Aakar Books, Delhi. 


\section{Instructions for the MOBI treatment ${ }^{1}$}

\section{General Information}

- Please read these instructions carefully and completely.

- Please do not talk to your neighbors and keep quiet during the entire experiment.

- Raise your hand if you have a question. One of us will come to you.

- All participants in the experiment have been given the same instructions.

\section{Introduction}

- In this experiment you will repeatedly make decisions. By doing so you can earn money.

- Your gains are measured in Talers. How much you earn depends on your decisions.

- At the end of the experiment your total sum of Talers will be determined by an initial endowment plus the number of Talers you earned in each round.

- At the end of the experiment you will receive 1 euro in cash for every 6 Talers. In addition, each participant will receive a participation fee of 4 euros.

- During the entire experiment, anonymity among participants and instructors will be kept.

- The experiment consists of 12 rounds.

- Before the experiment starts, we will ask you several questions via your computer screen which refer to possible situations in the experiment. For each question that you answer, you will earn one Taler. The funds earned after answering the questions will constitute your initial endowment.

\section{Description of the experiment}

- In this experiment, you can earn income by expending work effort. Your income will depend on the amount of work effort and on your wage per unit of work effort.

- Your work effort will be measured by the number of units of effort you choose to expend. You will choose the units of work effort in each round of the experiment.

- Your wage per unit of work effort will be assigned to you by the computer. Your wage rate can be either low ( 0 Taler per unit of effort), medium (3 Taler per unit of effort), or high (6 Taler per unit of effort).

- You will be randomly assigned your wage rate at the beginning of each round of the experiment.

- Your income from work effort will be higher the more units of effort you choose to expend. Your entire income from work will be subject to a tax. The collected tax revenues will be redistributed among the participants of the experiment.

\footnotetext{
${ }^{1}$ The experiment was conducted in German. The translated instructions for the MoBI treatment subsume the instructions for the other treatments, which are a shortened form of this version.
} 
- Each unit of work effort carries a cost. The work effort cost is higher the more units of effort you choose to expend. This cost will be subtracted from your after-tax income (i.e. your income minus your tax payment).

\section{Setup of the experiment}

- In each round, three participants of the experiment will form a group.

- In each group, there will be exactly one participant with a low wage, one participant with a medium wage and one participant with a high wage per unit of work effort.

- In the experiment, the two co-players in your group are not real participants of the experiment. Instead, the roles of the two co-players in your group will be performed by computers. The computer decides regarding the roles of the two other co-players, so that the gains of those two players will be highest.

- At the beginning of each round, you will be randomly assigned a wage rate. Henceforth, it will be randomly decided at the beginning of each round whether you will receive a low, medium or high wage per unit of work effort.

- Each round consists of two stages:

- In the first stage, each participant states his preferred tax rate.

- After having stated your tax rate, you will be assigned a new wage rate in 3 out of 4 cases (that is, with a probability of $75 \%$ ). This new wage rate will be again either low, medium or high, and it will again be randomly assigned. It can, but need not differ from your initial wage rate.

- In the second stage, each participant chooses how much units of work effort he wants to expend. At the end of each round, the number of Talers you have earned in this round will be displayed.

The following section describes the two stages of the experiment in greater detail.

\section{Stage 1: Choice of the tax rate}

- During the experiment, three participants form a group. The roles of the two co-players in your group will be performed by computers.

- In each group, there will be one participant with a low wage rate, one participant with a medium wage rate and one participant with a high wage rate.

- All three participants simultaneously state a tax rate that they would like to implement in their group. You choose the tax rate as an integer between 0 and 100; the number between 0 and 100 corresponds to the percentage of your income that has to be paid as tax.

- The computer then compares the three proposed tax rates within a group.

- In most cases, the computer will select the median of the three proposed tax rates for all members of the group. 
- For example, if the proposed three tax rates within a group are $7 \%, 25 \%$ and $30 \%$, the computer would implement a tax rate of $25 \%$ for all members of the group.

- In case the proposed three tax rates within a group are $18 \%, 64 \%$ and $65 \%$, the tax rate for the group would be $64 \%$.

- Note that the chosen tax rate will not be the average proposed tax rate, but the median proposed tax rate.

- In some cases, the computer will select the lowest of the three proposed tax rates or the highest of the three proposed tax rates for all members of the group.

- If the members of a group propose tax rates 1,2 and 3 - where tax rate 1 will be the lowest, tax rate 2 the median and tax rate 3 the highest of the three proposed tax rates - the selection by the computer will be as follows:

- In 8 out of 10 cases (i.e. with a probability of $80 \%$ ): $\quad$ Tax rate 2 will be selected In 1 out of 10 cases (i.e. with a probability of 10\%): Tax rate 1 will be selected In 1 out of 10 cases (i.e. with a probability of 10\%): $\quad$ Tax rate 3 will be selected

- At the beginning of stage 2, all members of the group will be displayed the selected tax rate. This tax rate will be applied for each participant of the group.

- The selection of the tax rate takes place separately for each group.

- After having chosen a tax rate, you will be assigned a new wage in 3 out of 4 cases (that is, with a probability of $75 \%$ ).

- If you are assigned a new wage rate, you can obtain either a low, a medium, or a high wage per unit of work effort.

- If you are assigned a new wage rate, the two co-players in your group will also be assigned a new wage rate.

- In any case, there will always be exactly one participant with a low wage rate, one participant with a medium wage rate and one participant with a high wage rate in your group.

\section{Stage 2: Choice of work effort}

- At the beginning of stage 2 , all members of the group will see the selected tax rate on their display.

- In case your wage rate has changed, you will be informed via your computer screen, and you will be shown your new wage per unit of work effort.

- All participants simultaneously choose the work effort they want to expend. The amount of work effort is chosen as a number between 0 and 6 . By expending more units of work effort, you are able to earn more income.

- Each additional unit of work effort carries a cost which is subtracted from your after-tax income. Thus, more work effort also involves a higher cost. 
- Finally, your profit will be determined during this round. Your profit depends on your work effort, the work effort of the co-players in your group, and the selected tax rate.

- Keep in mind: If your wage rate has changed between the first and the second stage, your profit will only depend on the wage rate that is valid in the second stage.

The following section describes how your profit is calculated.

\section{Calculation of your profit}

- Your profit is determined by the following elements:

- Your income from work effort

- minus your tax payment

- minus your cost of work effort

- plus a transfer income that is financed by the tax payments of the two co-players in your group.

- Your income from work effort depends on your work effort and on your wage rate. The payment of taxes is not yet considered within your income from work effort.

- The wage rate of each participant can either be low, medium, or high. A low wage rate has a value of 0 Taler per unit of work effort, a medium wage rate has a value of 3 Talers per unit of work effort, and a high wage rate has a value of 6 Talers per unit of work effort.

- You will choose by yourself the units of work effort in each round. Your wage rate will be assigned to you by the computer.

- If your wage rate has changed between the first and the second stage, your profit will only depend on the wage rate assigned in the second stage.

- Your income from work effort is calculated by multiplying the wage rate by the number of units of work effort expended:

Income from work $=$ wage per unit of work effort $\times$ units of work effort

In the following table, your income from work effort is calculated for different decisions on how much work effort you choose to expend. Please note that the units of work effort may be chosen as any possible number between 0 and 6 .

\begin{tabular}{|l||c|c|c|c|c|c|c|}
\hline Number of units of work effort & 0 & 1 & 2 & 3 & 4 & 5 & 6 \\
\hline \hline Income from work effort for a low wage rate & 0 & 0 & 0 & 0 & 0 & 0 & 0 \\
\hline Income from work effort for a medium wage rate & 0 & 3 & 6 & 9 & 12 & 15 & 18 \\
\hline Income from work effort for a high wage rate & 0 & 6 & 12 & 18 & 24 & 30 & 36 \\
\hline
\end{tabular}

- The amount of taxes you will have to pay will be determined by the tax rate valid for your group. 
- Your tax payment is calculated by multiplying your income from work effort by the tax rate:

Tax payment $=$ tax rate $\times$ income from work effort

$$
=\text { tax rate } \times \text { wage rate } \times \text { work effort }
$$

- The units of work effort you choose to expend create a cost, which is subtracted from your income after taxes. This cost is calculated as follows:

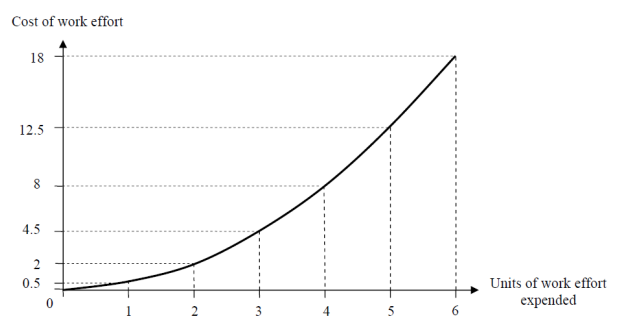

- You will receive a transfer income that is financed by the tax payments of the co-players in your group. Each participant receives a transfer income equal to half of the tax payments of the two other group members:

- Transfer income $=0,5 \times$ tax payments of the two co-players

$$
=0,5 \times \text { tax rate } \times \text { income from work effort of the two co-players }
$$

- Altogether, your profit in one round is determined as

- Profit $=$ income from work effort

$$
\begin{aligned}
& \text { - tax payment } \\
& - \text { cost of work effort } \\
& + \text { transfer income }
\end{aligned}
$$

\section{Sequence of actions in the experiment}

- Each group in this experiment consists of three participants.

- In each group, there will be exactly one participant with a low wage rate, one participant with a medium wage rate and one participant with a high wage rate.

- In the experiment, the two co-players in your group will be simulated by computers.

- In stage 1, the computer chooses a preferred tax rate for each of your co-players. This happens simultaneously to your choice of a preferred tax rate.

- Then, one of the proposed tax rates will be selected as the tax rate valid for your group in this round.

- Afterwards, the computer will choose the units of work effort for each of your co-players.

- The computer decides regarding the roles of your two co-players so that the gains of those two players will be highest. 
- In each round, you and your co-players will be assigned a new wage rate.

- At the beginning of each round, your wage rate will be displayed.

- Afterwards, you will state the tax rate that you would like to implement for your group in this round. You will have to enter your preferred tax rate in the corresponding text field and confirm this choice by clicking the "OK" button.

- The computer chooses the tax rate out of the three proposed tax rates within a group (your preferred tax rate and the preferred tax rates of your co-players). In most cases, the computer will select the median of the three proposed tax rates, but in some cases, the computer will select the lowest or the highest of the three proposed tax rates.

- After having chosen a tax rate, you will be assigned a new wage rate in 3 out of 4 cases (that is, with a probability of $75 \%$ ).

- Then, the tax rate to be implemented in your group in this round will be displayed. If your wage rate has changed, you will be informed by the computer and shown your new wage rate.

- Each participant then chooses his work effort. You will have to enter your work effort in the corresponding text field and confirm this choice by clicking the "OK" button.

- Please note: As additional information, the computer will display a table in which the following elements are calculated for different choices of work effort you can make: resulting income from work effort, resulting tax payment, resulting cost of work effort. Your transfer income will depend on the work effort expended by the co-players in your group.

- At the end of each round, you will be shown the following information:

- own proposed tax rate

- selected tax rate for your group

- units of work effort you expended

- your profit in this round

The following figure summarizes the sequence of actions in one round.

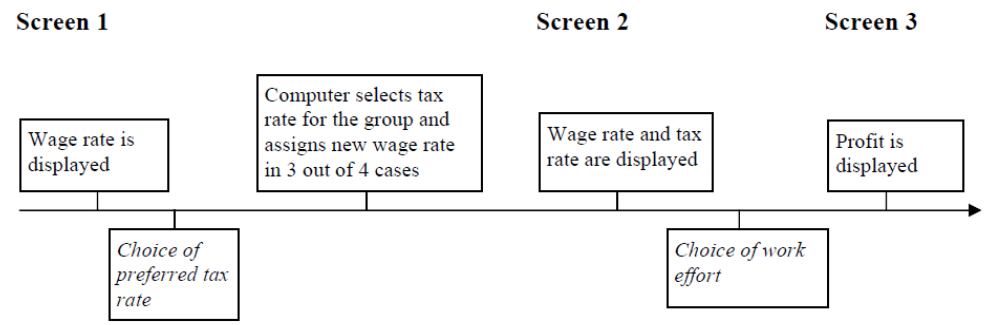

- Before the experiment starts, we will ask you several questions via your computer screen which refer to your actions in the experiment. By answering the questions, you can earn your initial endowment. 